\title{
EFEKTIVITAS TEKNIK RELAKSASI TERHADAP PENURUNAN NYERI DISMENOREA PADA REMAJA PUTRI DI SMPN 1 KARTOHARJO MAGETAN
}

\author{
Astin Nur Hanifah ${ }^{1}$, Syahda Febby Kuswantri ${ }^{1}$ \\ ${ }^{1}$ Prodi DIII Kebidanan Magetan Poltekkes Kemenkes Surabaya
}

\begin{abstract}
Info Artikel Abstrak
Genesis Naskah:

Submissions: 03-11-2020

Revised: 12-11-2020

Accepted: 12-11-2020

\section{Kata Kunci:}

Nyeri Dismenorea,

Remaja Perempuan,

Teknik Relaksasi

Dismenorea terbagi menjadi dismenorea primer yaitu nyeri karena kontraksi miometrium akibat produksi prostaglandin tanpa kelainan pada pelvis, dismenorea sekunder dimana nyeri disertai kelainan pada pelvis. Prevalensi dismenorea di Indonesia sebesar $64,25 \%$ yang terdiri dari 54,89\% dismenorea primer dan 9,36\% dismenorea sekunder. Dilaporkan $30-60 \%$ remaja wanita yang mengalami dismenorea, sebanyak $7-15 \%$ tidak pergi ke sekolah. Berdasarkan hasil wawancara dan studi pendahuluan yang dilakukan oleh siswi di SMPN 1 Kartoharjo Magetan Tahun 2020 dan diambil secara acak, didapatkan hasil bahwa dari 104 siswi didapatkan 58 siswi mengalami dismenorea dan tidak mengikuti pelajaran dikelas. Rancangan penelitian adalah eksperimen semu (Quasi Experiment). Besar sampel berdasarkan total populasi sejumlah 58 responden. Variabel bebas adalah Teknik Relaksasi. Variabel Terikat adalah Nyeri Dismenorea. Pengumpulan data dengan menggunakan kuesioner. Penelitian ini menggunakan one group pretest-posttest dengan cara memberikan pretest (pengamatan awal) sebelum diberikan intervensi, kemudian setelah diberikan intervesi dilakukan posttest. Analisis data menggunakan Uji Paired Sample T-Test untuk melihat perbedaan sebelum dan sesudah dilakukan intervensi. Hasil penelitian menunjukkan bahwa siswi sebelum diberikan Teknik Relaksasi didapatkan tingkat nyeri 5 dan 6 yang merupakan nyeri sedang setelah dilakukan intervensi mengalami penurunan menjadi 2 dan 3 (nyeri ringan). Siswi dapat berperan aktif dalam membantu menanggulangi masalah nyeri haid dengan mengajarkan Teknik Relaksasi pada remaja lainnya, siswi bisa mengatasi pada saat nyeri haid dengan melakukan Teknik Relaksasi secara teratur pada saat Dismenorea.
\end{abstract}

\section{EFFECTIVENESS OF RELAXATION TECHNIQUES ON REDUCTION OF DYSMENORRHOEA PAIN IN GIRLS ADOLESCENT AT SMPN 1 KARTOHARJO MAGETAN}

\section{Keywords: \\ Relaxation Techniques, \\ Girls Adolescent, \\ Dysmenorrhoea Pain}

\begin{abstract}
Dysmenorrhoea is divided into primary dysmenorrhoea, namely pain due to myometrial contraction due to prostaglandin production without abnormalities in the pelvis, secondary dysmenorrhoea where pain is accompanied by abnormalities in the pelvis. The prevalence of dysmenorrhoea in Indonesia is $64.25 \%$ consisting of $54.89 \%$ primary dysmenorrhea and $9.36 \%$ secondary dysmenorrhoea. It is reported that 30-60\% of young women who experience dysmenorrhoea, as much as 7 $15 \%$ do not go to school. Based on the results of interviews and preliminary studies conducted by students at SMPN 1 Kartoharjo Magetan in 2020 and taken randomly, it was found that out of 104 students, 58 students had dysmenorrhoea and did not attend class lessons. This research is a quasiexperimental (Quasi Experiment). The design of this study was a pre and
\end{abstract}


postest design. The sample size is based on a total population of 58 respondents. The independent variable is the Relaxation Technique. The dependent variable is Dysmenorrhoea Pain. Data collection using a questionnaire. Data analysis used Paired Sample T-Test. The results showed that before being given the relaxation technique, the students had pain levels of 5 and 6 which were moderate pain after the intervention decreased to 2 and 3 (mild pain). Students can play an active role in helping to overcome the problem of menstrual pain, especially in adolescents by doing the Relaxation Technique, students can overcome menstrual pain by doing relaxation techniques and warm compresses regularly during dysmenorrhea.

\section{Korespondensi Penulis:}

Astin Nur Hanifah

Prodi DIII Kebidanan Magetan Jalan Letjen S Parman No 1 Tambran Magetan Jawa Timur

Email: astinnur1980@gmail.com 


\section{PENDAHULUAN}

Prevalensi dismenorea di Indonesia sebesar $64,25 \%$ yang terdiri dari $54,89 \%$ dismenorea primer dan 9,36\% dismenorea sekunder. Dilaporkan 30-60\% remaja wanita yang mengalami dismenorea, sebanyak 7-15\% tidak pergi ke sekolah atau bekerja (Larasati dan Faridah, 2016:80). Berdasarkan hasil wawancara terhadap guru dan studi pendahuluan yang dilakukan oleh siswi di SMPN 1 Kartoharjo Magetan Tahun 2020 dan diambil secara acak, didapatkan hasil bahwa dari 104 siswi didapatkan 58 siswi mengalami dismenore dan tidak mengikuti pelajaran dikelas.

Dismenorea primer disebabkan akibat pelepasan sel-sel telur (ovulasi) dari indung telur (ovarium) berhubungan dengan gangguan keseimbangan hormon (Devi, 2012: 19). Didukung hasil penelitian oleh Larasati \& Faridah (2016) di Lampung menyatakan bahwa peningkatan prostaglandin menyebabkan hipertonus dan vasokonstriksi miometrium, sehingga terjadi iskemia dan nyeri perut bagian bawah.

Nyeri saat menstruasi menimbulkan ketidaknyamanan pada wanita yang mengakibatkan wanita tersebut tidak dapat melakukan aktifitas sehari-hari. Mahasiswi yang mengalami dismenorea saat menstruasi akan mengakibatkan penurunan konsentrasi belajar dan motivasi belajar bahkan izin pulang sekolah dikarenakan tidak tahan dengan dismenorea yang dirasakan (Beddu, Sitti \& Viqy, 2015:17).

Upaya penanganan dismenorea dapat dilakukan dengan terapi farmakologis dan non farmakologis. Terapi farmakologis dengan menggunakan obat analgesik dan obat penghambat pengeluaran hormon prostaglandin (Hartati, Walin \& Esti, 2015:794). Salah satu metode non farmakologis yang dapat digunakan sewaktu-waktu saat muncul adalah dengan teknik relaksasi. Relaksasi merupakan teknik pengendoran atau pelepasan ketegangan, misalnya: bernafas dalam dan pelan. Selain dapat menurunkan intensitas nyeri, teknik relaksasi nafas dalam juga dapat meningkatkan ventilasi paru dan meningkatkan oksigen darah (Smeltzer \& Bare, 2002). Prinsip yang mendasari penurunan nyeri oleh teknik relaksasi nafas dalam terletak pada fisiologi sistem saraf

Otonom yang merupakan bagian dari sistem saraf perifer yang mempertahankan homeostatis lingkungan internal individu. Penggunaan kompres hangat diharapkan dapat meningkatkan relaksasi otot-otot dan mengurangi nyeri akibat spasme atau kekakuan serta memberikan rasa hangat lokal. Pada umumnya panas cukup berguna untuk pengobatan. Panas meredakan iskemia dengan menurunkan kontraksi dan meningkatkan sirkulasi. Kompres hangat dapat menyebabkan pelepasan endorfin tubuh sehingga memblok transmisi stimulasi nyeri (Devi, 2012: 19).

Pada kesempatan ini peneliti tidak melakukan penelitian pada semua manajemen nyeri. Peneliti hanya membatasi pada manajemen nyeri non farmakologis yaitu teknik relaksasi terhadap nyeri dismenorea.

Berdasarkan uraian dalam latar belakang di atas, maka peneliti merumuskan masalah "Bagaimanakah perbedaan intensitas nyeri teknik relaksasi terhadap nyeri dismenorea ?" Tujuan Penelitian menganalisis efektifitas teknik relaksasi terhadap penurunan nyeri dismenorea.

\section{METODE}

Jenis penelitian ini merupakan penelitian eksperimen semu (Quasi Experiment. Menurut (Notoatmodjo, 2010) rancangan eksperimen semu tidak memiliki ciri-ciri rancangan eksperimen sebenarnya karena variabel yang seharusnya dikontrol tidak dapat dilakukan atau sulit dilakukan. Tahapan. Etik penelitian diajukan pada komisi etik Poltekkes Kemenkes Surabaya. Penelitian ini menggunakan one group pretest-posttest dengan cara memberikan pretest (pengamatan awal) sebelum diberikan intervensi, kemudian setelah diberikan intervesi dilakukan posttest (pengamatan akhir) (Hidayat A, 2011).

Pretest Perlakuan Posttes

\begin{tabular}{|lll|}
\hline O1 & $\mathrm{X}$ & $\mathrm{O} 2$ \\
\hline
\end{tabular}

Populasi penelitian ini siswi SMPN 1 Kartoharjo Magetan Tahun 2020 bulan MaretMei 2020 yang mengalami dismenorea dengan besar populasi 58 orang. Pengukuran Nyeri dismenhoroe dilakukan sebelum dan 
sesudah dilakukan Teknik Relaksasi. Identifikasi nyeri dismenorea (checklist skala nyeri Bourbanis dengan skala nyeri $1,2,3,4,5,6,7,8,9,10)$. Data yang telah ditabulasi dianalisa secara deskriptif. Untuk menguji hipotesis penelitian dilakukan 2 uji statistik yaitu Uji Paired Sample T-Test dan Uji Independent Sample T-Test.

Perbedaan antara skala nyeri sebelum dilakukan teknik relaksasi dengan sesudah dilakukan teknik relaksasi di uji dengan menggunakan Uji Paired Sample T-Test.

\section{HASIL}

Tabel 1. Perbedaan Tingkat Nyeri Haid Pada Remaja Putri di SMPN 1 Kartoharjo Magetan Sebelum dan Sesudah dilakukan Teknik Relaksasi Bulan Maret -April 2020

\begin{tabular}{|c|c|c|c|c|c|c|}
\hline & Meall & $\begin{array}{c}\text { Sttd. } \\
\text { Devination }\end{array}$ & $\begin{array}{l}\text { Stt. } \\
\text { Error } \\
\text { Meall }\end{array}$ & $I$ & Df & $\begin{array}{l}\text { Sig. }(-2 \\
\text { talled }\end{array}$ \\
\hline $\begin{array}{l}\text { Teknilk } \\
\text { Relahsasi } \\
\text { Pra } \\
\text { Intertensi } \\
\text { - } \\
\text { Telknilk } \\
\text { Relalksasi } \\
\text { Pasca } \\
\text { Interrensi }\end{array}$ & 2.37931 & 90292 & 16767 & 14.191 & 28 &, 000 \\
\hline
\end{tabular}

Pada Tabel diatas Hasil menggunakan Uji Paired Sample T-Test mengenai sebelum dan sesudah dilakukan Teknik Relaksasi didapatkan hasil nilai signifikansi yaitu 0,000 $(<0,05)$, maka disimpulkan ada perbedaan bermakna antara sebelum dan sesudah dilakukan Teknik Relaksasi

\section{PEMBAHASAN}

Berdasarkan data tersebut menunjukkan bahwa rata-rata tingkat nyeri remaja yang dilakukan Teknik Relaksasi mengalami penurunan, tingkat nyeri sebelum dilakukan Teknik Relaksasi sebesar 5 dan 6 (nyeri sedang), sedangkan setelah dilakukan Teknik Relaksasi rata-rata tingkat nyerinya menjadi 2 dan 3 (nyeri ringan) Sehingga dari data tersebut didapatkan selisih rata-rata tingkat nyeri yang merupakan nyeri ringan. Nilai skala nyeri 2 dan 3 menunjukkan bahwa rata-rata tingkat nyeri mengalami penurunan yaitu dari nyeri sedang (5 dan 6) menjadi nyeri ringan (3 dan 4). Peneliti melihat perubahan tingkat nyeri tersebut terjadi tidak hanya karena dengan Teknik Relaksasinya saja, tetapi dapat dilihat pada saat waktu melakukannya. Melakukan teknik relaksasi secara teratur dengan memperhatikan waktu untuk melakukannya sebaiknya dilakukan pada saat keadaan rileks, posisi yang nyaman, tenang, jangan terdapat beban didalam fikiran, dalam keadaan berbaring diatas tempat tidur dan juga bisa sambil menonton tv dengan durasi yang tidak dapat ditentukan ketika nyeri haid muncul. Salah satu manfaat yang didapat setelah melakukan teknik relaksasi nafas dalam adalah mengurangi atau bahkan menghilangkan rasa nyeri yang terjadi pada individu tersebut, kententraman hati, dan berkurangnya rasa cemas, juga praktis dalam melakukan teknik relaksasi nafas dalam tersebut tanpa harus mengeluarkan biaya. Hal ini sejalan dengan penelitian oleh Nevi Sulastri, Tri Susilowati \& Norman Wijaya Gati (2019) di Surakarta yang menyatakan bahwa teknik relaksasi yang dilakukan secara benar bagaimana cara melakukannya dan tahapannya serta waktu yang diperlukan maka dapat menurunkan intensitas nyeri dan dapat meningkatkan ventilasi paru dan meningkatkan oksigenasi darah.

\section{KESIMPULAN DAN SARAN}

Hasil Pengukuran Tingkat Nyeri haid sebelum dilakukan Teknik Relaksasi pada remaja putri SMPN 1 Kartoharjo mendapatkan skala nyeri dengan intensitas nyeri sedang dan untuk hasil pengukuran tingkat nyeri sesudah dilakukan Teknik Relaksasi pada remaja putri SMPN 1 Kartoharjo mengalami penurunan dan intensitas nyeri menjadi nyeri ringan.

Informasi yang diperoleh dari penelitian ini dapat diaplikasikan oleh guru khususnya guru piket UKS di SMPN 1 Kartoharjo sehingga siswi yang mengalami Dismenorea mendapatkan pelayanan khususnya mengenai Teknik Relaksasi Sehingga dapat mengurangi nyeri Dismenorea yang dialami. 


\section{DAFTAR PUSTAKA}

Anonim. 2015. Kesehatan Reproduksi. Jakarta. Yogjakarta : Nuha Medika.

Arfa, Aningsih. 2018. Menurunkan Nyeri Dismenore dengan Relaksasi. Jurnal Keperawatan Vol VIII No 2 : 137-141. 2011

Dinkes Jawa Timur. 2017. Profil Kesehatan Provinsi Jawa Timur Tahun 2016. Surabaya : Dinas Kesehatan Provinsi Jawa Timur.

Dinkes Magetan. 2019. Profil Kesehatan Kabupaten Magetan 2018. Surabaya: Dinas Kesehatan Kabupaten Magetan.

Devi. 2012: 21-22. Buku Ajar Psikologi Kebidanan. Unmuh Ponorogo Press.

Dwienda et al. 2014. Buku Ajar Asuhan Kebidanan Neonatus/Bayi, Balita, Anak Prasekolah untuk Para Bidan. Yogyakarta: Deepublish.

Kemenkes RI. 2013. Riset Kesehatan Dasar Riskesdas 2018. Jakarta: Penelitian dan Pengembangan Kesehatan Kemenkes RI

Manuaba, I. A. C., Manuaba, I. B. G. F., \& Ida Bagus Gde Manuaba. 2012. Ilmu Kebidanan, Penyakit Kandungan, dan $K B$. 2nd ed. Jakarta: Penerbit Buku Kedokteran EGC.

Maternity, Arum Dwi, dan Nita Evrianasari. 2018. Asuhan Kebidanan Neonatus, Bayi, Balita dan Anak pra Sekolah. Yogyakarta: CV Andi offset

Maryunani, Anik. 2013. Asuhan Kegawatdaruratan Maternal \& Neonatal. Jakarta. Trans Info Medika.

Muslihatun, Wafi Nur. 2010. Asuhan Neonatus Bayi dan Balita. Yogyakarta : Fitramaya

Nisak, Noor. 2017: 80. Konsep Penatalaksanaan Nyeri. Jakarta : EGC. 2007.

Nursalam. 2017. Metode Penelitian Ilmu Keperawatan. Jakarta: Salemba Medika.

Notoatmojo. S. 2012. Metode Penelitian Kesehatan. Jakarta: Rineka Cipta

Nugraha. 2017. Menurunkan Nyeri Dismenore dengan Kompres Hangat. Jurnal Keperawatan Vol VII No 2 : 137-141. 2012
Nugroho, Heru Santoso Wahito. 2015. Metode Penelitian Dan Statistika Dasar. Politeknik Kesehatan Kemenkes Surabaya.

Nurhidayati. 2013. Belajar dan Pembelajaran. Jakarta: Rineka Cipta

Pemerintah Indonesia (2003). Undang-Undang Republik Indonesia Nomor 20 Tahun 2003 Tentang Sistem Pendidikan Nasional Pasal 25 Ayat 2 dan Pasal 70. Jakarta: Sekretariat Negara Republik Indonesia.

Proverawati, Atikah. 2010. BBLR Berat Badan Lahir Rendah. Yogyakarta: Nuha Medika.

Riadi. 2013. Metode Penelitian Kesehatan. Jakarta:Medikapusta

Ryantama. 2017. Kegawatan Maternal Dan Neonatal. Yogyakarta: Deepublish

Sembiring, JB.2017. Buku Ajar Neonatus, Bayi, Balita, Anak Pra Sekolah Ed. 1, Cet. 1. Yogyakarta : Deepublish

Suparyanto. 2018. Konsep paritas/partus. Retrived from https://www/doc/76017024/konsepparitas diaskes pada tanggal 01 Februari 2020 pukul: 16.00 WIB.

Swarjana, I Ketut. 2012. Metodologi Penelitian Kesehatan. Yogyakarta: CV. Andi Offset.

Triana, Ani. 2015. Kegawatan Maternal Dan Neonatal. Yogyakarta: Deepublish.

Wiknjosastro, G. H. 2008. Asuhan Persalinan Normal. Jakarta: PT Bina Pustaka Sarwono Prawirohardjo. 